\title{
APPLICATION OF LASER SCANNING TECHNOLOGY IN CREATION OF 3D CITY MODELS
}

\author{
Stevan Milovanov', Igor Ruskovski' \\ Received: November 15, 2017 | Accepted: December 10, 2017
}

\begin{abstract}
Laser scanning technology is considered to be a fairly new active remote sensing technology and it finds its application in various fields. The data acquired trough terrestrial or aerial laser scanning is beneficial in representation of three-dimensional space. Huge dataset allows detailed modeling of single objects or even whole cities. The data can be stored in 3D database and displayed trough many applications.
\end{abstract}

Keywords: Laser scanning, TLS, 3D database, smart city, 3D modeling

\section{INTRODUCTION}

Contemporary age has brought us many technologies and many of them found their application in the field of geodesy. The data in geodetic manner is no longer enough. Instead, the data that carries various information about the object of interest is important as well.

Light Detection and Ranging - LiDAR is fully automatic, active, optical - mechanical process of geospatial data acquisition. Due to the best accessibility of larger area and higher mobility of the scanner, most often the scanning is performed from an aerial platform. When it comes to restricted areas, slopes and also scanning in order to create high detailed building models or statues, scanning is done from static positions. According to this, we distinguish two types of scanning: aerial laser scanning and terrestrial laser scanning (Internet 2).

The result of scanning is, contrary to classic geodetic methods, mass points with three-dimensional coordinates called point cloud. This type of data requires special attention and experience during software processing. 


\section{LASER SCANNING TECHNOLOGY}

Laser scanning is a modern technology meant for geospatial data acquisition in form of three-dimensional coordinates in space. The information about the shape or look of real world object is gathered. That data can later be used to create digital, two-dimensional drawings or three-dimensional models that have huge application. The ain advantage of this technology over others is the ability to gather large amount of points with high precision in a relatively short time.

Aerial laser scanning is one of the recently developed technologies of surveying and it finds its application in several areas of industry. Scanner is mounted on aerial platform that flies over the terrain and gets the data. Main principle of this technology is: laser ray is emitted and the exact time of sending is recorded. Reflected ray is later detected in the system and the time is recorded again. Based on the velocity of the ray and measured time it is possible to determine the distance. Knowing the position and orientation of the sensor, $\mathrm{X} \mathrm{Y}$ and $\mathrm{Z}$ coordinates for the point are calculated (Internet 2).

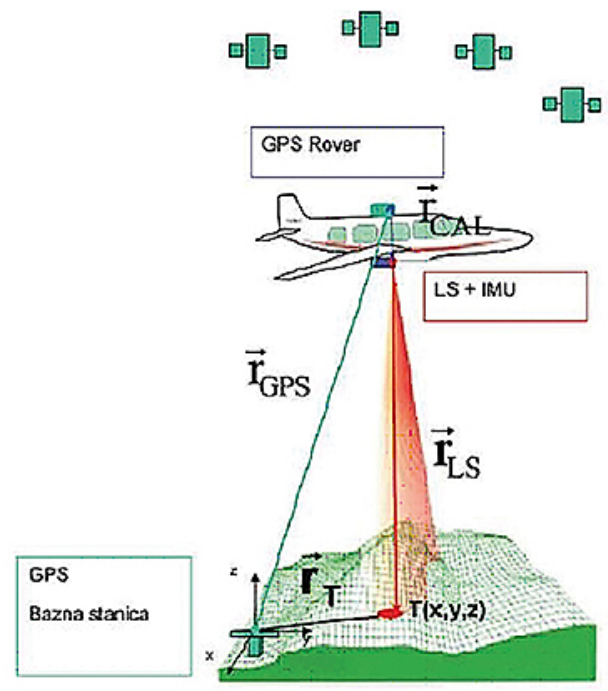

Figure 1. Aerial laser scanning system

Figure 1 shows components of the system for aerial laser scanning. Alongside laser scanner that is meant for point collection, there is a GNSS receiver to record the position of the platform, inertial measurement unit to measure orientation, RGB/NIR camera and computer unit. It is necessary to have GNSS base station to send differential corrections.

Terrestrial laser scanners are instruments that send an array of laser impulses based on determined time to measure the distance and horizontal and vertical angle from the instrument to point in space. Large number of point, sometimes even several million, is organized into georeferenced point cloud. Scanner is set near the surface. This method is convenient for scanning of objects, industrial facilities, pipelines, etc. (Govedarica, 2017). 


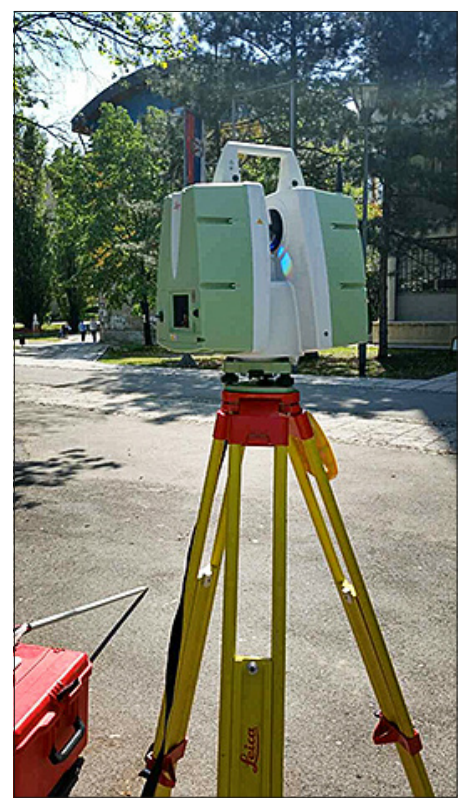

Figure 2. Terrestrial laser scanner

\section{RESULTS AND DISCUSION}

The result of aerial laser scanning is point cloud that can be the source of many information and also the base for further processing and creation of city models. First step of data processing is classification that can be done in arbitrary number of classes that are defined for specific application. 2D vectorization can be done based on images from RGB/NIR camera that is a part of LiDAR system. Figure 3 shows part of the city where $2 \mathrm{D}$ vectorization was done based on the images, but also $3 \mathrm{D}$ vectorization of buildings based on previously classified point cloud.

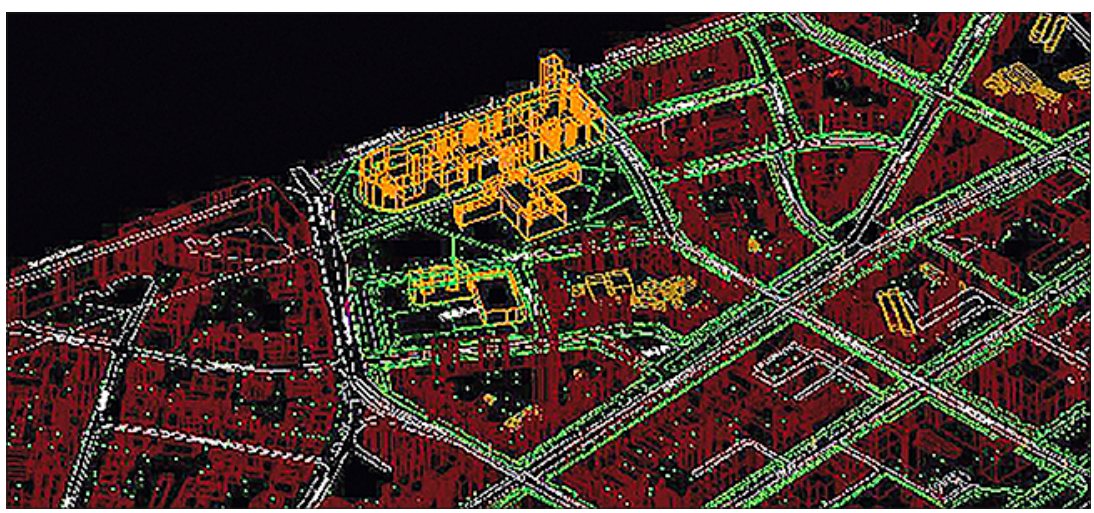

Figure 3. 2D and 3D vectorization of surrounding of the Vojvodina Government building in Novi Sad 


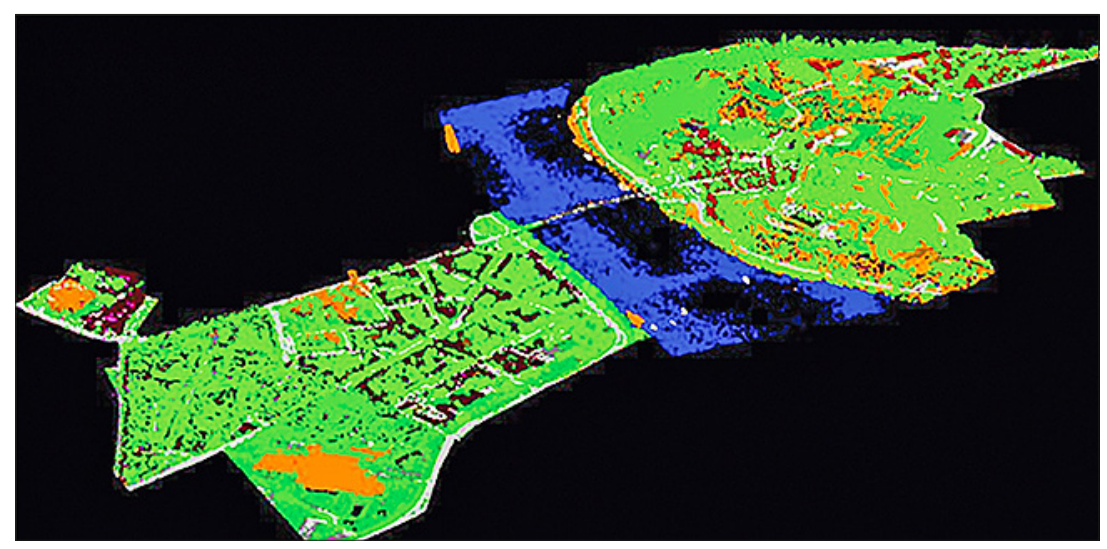

Figure 4. Classified point cloud of city centre and Petrovaradin fortress

Figure 4 shows an example of fully processed point cloud after detailed classification. The data prepared in this way will be used in creation of virtual city.

$3 \mathrm{D}$ modeling is one of the most important and most popular export forms of laser scanning. It includes the development of 3D objects using various mathematical processes. One of the goals of this paper was to create a high detailed 3D model of building fronts. High detail request implied the modeling based on meshes, which means that all points were connected into triangles that form surfaces. An example is shown on figure 5.

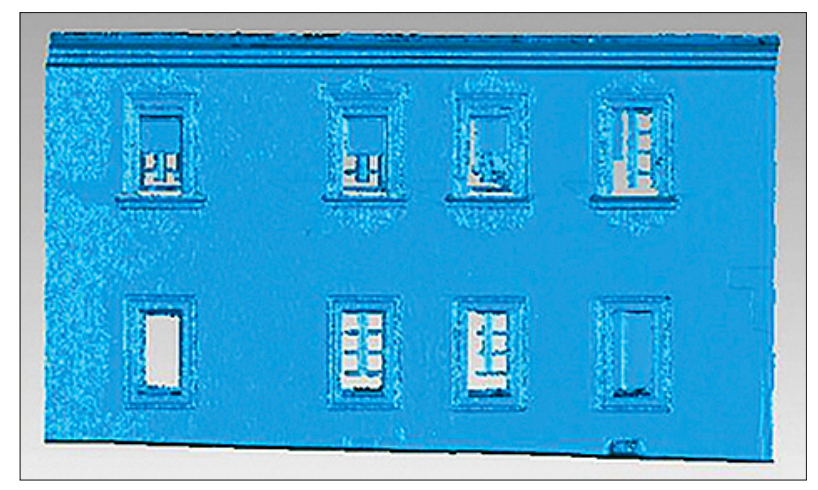

Figure 5. 3D Model of a building front beneath Petrovaradin fortress

One way to visualize scanned data is trough web based applications designed to allow users to see the data and find out information they need from the point cloud. The main advantage of this approach is that it allows the users to share their datasets with clients and public without the need to install additional applications or download the data. Figures 6 and 7 show an example of published data trough Potree internet based application and its functionalities. Potree was used to publish the data for the university campus in Novi Sad (Internet 4).

CityGML is an open standardised data model and exchange format to store digital $3 \mathrm{D}$ models of cities and landscapes. It defines ways to describe most of the common 3D 
features and objects found in cities (such as buildings, roads, rivers, bridges, vegetation and city furniture) and the relationships between them. It also defines different standard levels of detail (LoDs) for the 3D objects, which allows the representation of objects for different applications and purposes (Internet 1). Most important application of CityGML is in creating city database - CityDB, which stores CityGML in databases.

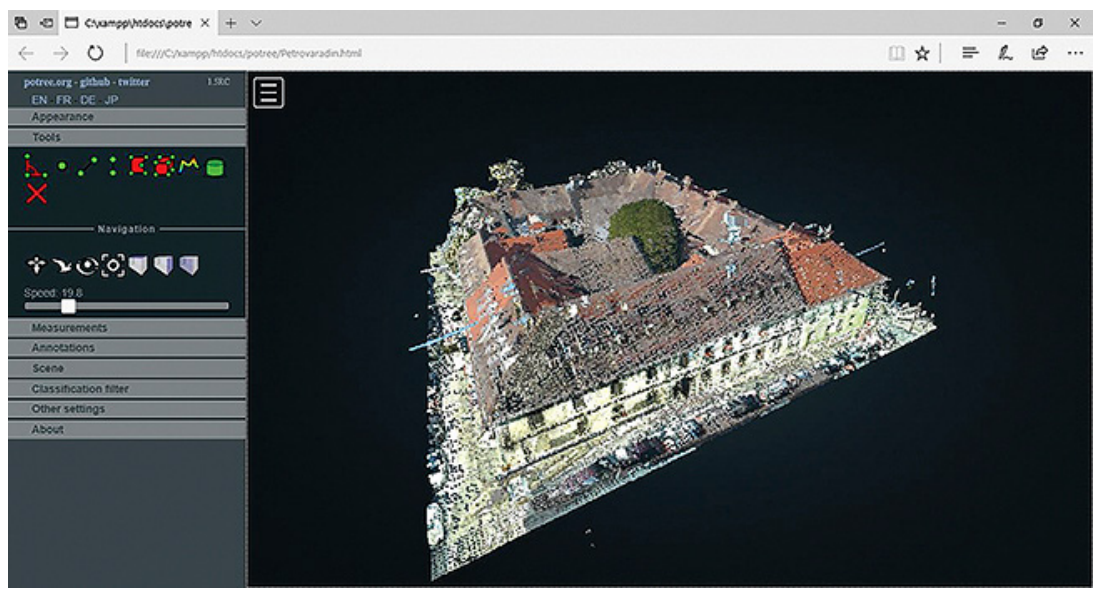

Figure 6. Published point cloud for a part of the city beneath Petrovaradin fortress

3D City Database is a free geo database to store, represent, and manage virtual 3D city models on top of a standard spatial relational database (Internet 3). This database implements CityGML standard that simplifies complex analysis that reach far beyond main tasks of visualization.

The content that was created trough 3D vectorization can be exported in different formats. The data used in this paper was exported to GML. After that, the content was

a)

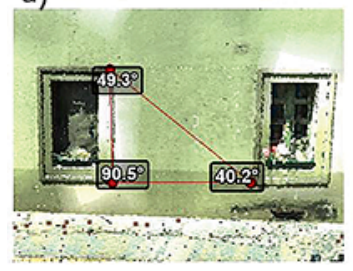

d)

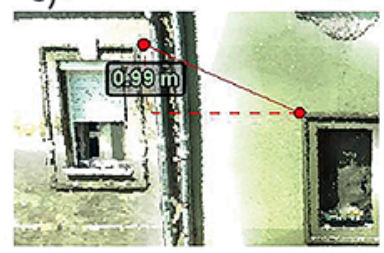

b)

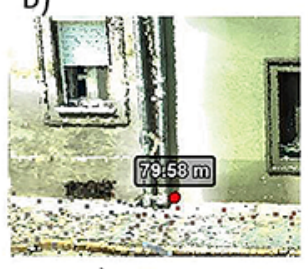

e) c)

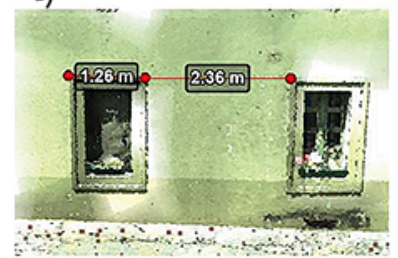

2.4.

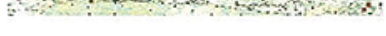

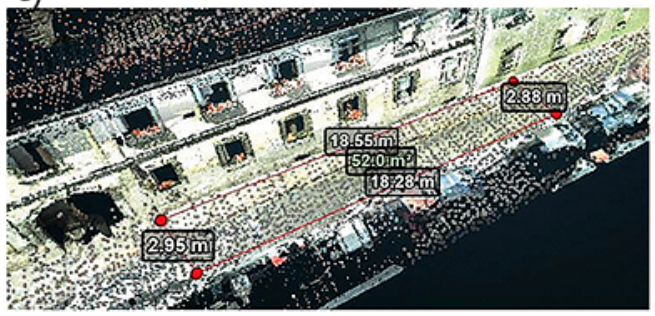

Figure 7. Functionalities of Potree shown on an object beneath Petrovaradin fortress 


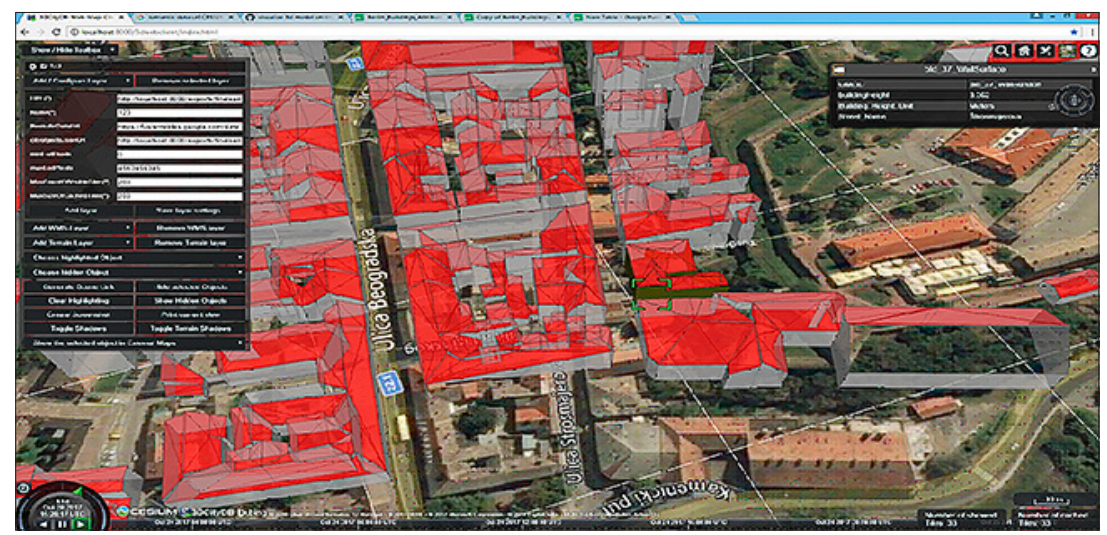

Figure 8. Published data trough Cesium

transformed and loaded into previously created database trough FME transformator. The database used in this case was postgres geospatial database with 3DcityDB extension. The result is fully loaded database which contains 3D models of objects. This data can then be published trough Cesium publisher - open source JavaScript library used for creating a 3D globe and maps (figure 8).

\section{CONCLUSION}

Gathering information about our environment and displaying them in an adequate way allows us to see our reality. This paper presents the advantages of the laser scanning technology. Huge amount of data was collected in a very short time which is impossible for any of the conventional surveying methods. Observation and analysis of the point cloud can provide many information without the need to visit the site.

The importance to display city area is rapidly growing. The users of geospatial data are requesting accurate, precise and updated data in shortest time period. New possibilities for realizing the environment are being opened up based on that information. 3D city models that include digital terrain model and objects are capable of providing the data to different fields of application. Environment protection, managing risks of natural disasters, 3D cadastre, urban planning are just some of the fields where 3D city models find their application.

\section{REFERENCES}

Gajski D. (2007): Osnove laserskog skeniranja iz zraka, Ekscentar, no. 10, pp. 16-22 Govedarica M. (2017). Literature on the course Laser scanning of terrain and objects,

Faculty of technical sciences in Novi Sad

Internet 1: CityGML, https://www.citygml.org/, downloaded 5.11.2017. 
Internet 2: LiDAR, http://web.pdx.edu/ jduh/courses/geog493f12/Week04.pdf , downloaded 5.9.2017.

Internet 3: 3D CityDB, https://www.3dcitydb.org/3dcitydb/3dcitydbhomepage/, downloaded 5.11.2017.

Internet 4: Published data for university campus in Novi Sad, http://geoinformatika.uns. ac.rs:8080/potree_priprema/examples/kampus_UNS.html. 